Article

\title{
Protective Malaria Vaccine in Mice Based on the Plasmodium vivax Circumsporozoite Protein Fused with the Mumps Nucleocapsid Protein
}

\author{
Rodolfo F. Marques ${ }^{1,+}+\mathbb{D}$, Alba Marina Gimenez ${ }^{1,2,+}$, Eduardo Aliprandini $^{3}$, Janaina T. Novais ${ }^{1}$, \\ Diego P. Cury ${ }^{4}$, Ii-Sei Watanabe ${ }^{4}$, Mariana R. Dominguez ${ }^{1}$, Eduardo L. V. Silveira ${ }^{1}{ }^{\mathbb{D}}$, \\ Rogerio Amino ${ }^{3}$ and Irene S. Soares ${ }^{1, *}$ \\ 1 Department of Clinical and Toxicological Analyses, School of Pharmaceutical Sciences, \\ University of São Paulo, São Paulo 05508-000 SP, Brazil; rodolfoferreira@usp.br (R.F.M.); \\ albamarinagimenez@gmail.com (A.M.G.); janaina.novais@usp.br (J.T.N.); maridmz04@gmail.com (M.R.D.); \\ eduardosilveira@usp.br (E.L.V.S.) \\ 2 Center of Cellular and Molecular Therapy, Federal University of São Paulo, São Paulo 04044-010 SP, Brazil \\ 3 Unit of Malaria Infection \& Immunity, Institut Pasteur, 75015 Paris, France; \\ eduardo.aliprandini@pasteur.fr (E.A.); rogerio.amino@pasteur.fr (R.A.) \\ 4 Department of Anatomy, Institute of Biomedical Sciences, University of São Paulo, \\ São Paulo 05508-000 SP, Brazil; diegocury@usp.br (D.P.C.); watanabe@icb.usp.br (I.-S.W.) \\ * Correspondence: isoares@usp.br \\ + These authors contributed equally to this work.
}

Received: 30 March 2020; Accepted: 16 April 2020; Published: 19 April 2020

check for updates

\begin{abstract}
Plasmodium vivax is the most common species of human malaria parasite found outside Africa, with high endemicity in Asia, Central and South America, and Oceania. Although Plasmodium falciparum causes the majority of deaths, P. vivax can lead to severe malaria and result in significant morbidity and mortality. The development of a protective vaccine will be a major step toward malaria elimination. Recently, a formulation containing the three allelic variants of the $P$. vivax circumsporozoite protein (PvCSP-All epitopes) showed partial protection in mice after a challenge with the hybrid Plasmodium berghei $(\mathrm{Pb})$ sporozoite, in which the PbCSP central repeats were replaced by the VK210 PvCSP repeats ( $\mathrm{Pb} / \mathrm{Pv}$ sporozoite). In the present study, the chimeric PvCSP allelic variants (VK210, VK247, and P. vivax-like) were fused with the mumps virus nucleocapsid protein in the absence $\left(\mathrm{NLP}_{-\mathrm{CSP}}\right)$ or presence of the conserved C-terminal (CT) domain of PvCSP (NLP-CSP $\mathrm{CT}$ ). To elicit stronger humoral and cellular responses, Pichia pastoris yeast was used to assemble them as nucleocapsid-like particles (NLPs). Mice were immunized with each recombinant protein adjuvanted with Poly (I:C) and presented a high frequency of antigen-specific antibody-secreting cells (ASCs) on days 5 and 30, respectively, in the spleen and bone marrow. Moreover, high IgG titers against all PvCSP variants were detected in the sera. Later, these immunized mice with NLP-CSP $\mathrm{CT}_{\mathrm{C}}$ were challenged with $\mathrm{Pb} / \mathrm{Pv}$ sporozoites. Sterile protection was observed in $30 \%$ of the challenged mice. Therefore, this vaccine formulation use has the potential to be a good candidate for the development of a universal vaccine against $P$. vivax malaria.
\end{abstract}

Keywords: malaria vaccine; Plasmodium vivax; circumsporozoite protein; mumps nucleoprotein

\section{Introduction}

Plasmodium vivax is the second most prevalent species causing malaria in the world, occurring mainly in South and Southeast Asia, the Western Pacific, the Eastern Mediterranean, Central America, and South America [1]. Recent data estimate that 7.5 million malaria cases are caused by P. vivax 
annually in the world, and nearly 2.5 billion people are living in areas at risk of this infection [1]. The mortality induced by $P$. vivax infection is considered to be very low when compared to $P$. falciparum infection. However, $P$. vivax-derived morbidity has significantly increased during the last few years due to the development of chloroquine resistance by the parasite [2]. In addition, several countries have reported an increase in the number of malaria cases with serious complications including anemia, respiratory distress syndrome, cerebral malaria, and malnutrition [3]. Although public health experts have considered the development of a malaria vaccine to be a research priority [4], clinical research for $P$. vivax vaccines has been mostly neglected. In fact, only a few trials for vaccines against $P$. vivax malaria have been performed [5].

The circumsporozoite protein (CSP) is the most prominent antigen on the surface of Plasmodium sporozoites. The most advanced malaria vaccine candidate, Mosquirix ${ }^{\mathrm{TM}}$ (RTS,S), was developed based on the conserved C-terminal domain and the central repeats domain of the P. falciparum CSP combined with the hepatitis B virus surface antigen (HBsAg). Its expression occurs in the virus-like particle (VLP) assemble that is conjugated with AS01E adjuvant [6]. In phase III clinical trials, the RTS, S vaccination resulted in a $30 \%-50 \%$ reduction in disease incidence and a $26 \%-35 \%$ prevention of cerebral malaria, though the duration of this efficacy was seen to be limited [7]. Immunological studies carried out 12 months post-RTS,S immunization demonstrated that protection against the first or recurrent malaria events was related to the generated anti-CSP IgG antibodies, which targeted repeat and C-terminal domains [8].

P. vivax CSP (PvCSP) comprises a central domain of tandem repeat sequences flanked by two non-repetitive conserved sequences, the $\mathrm{N}$ - and C-terminal domains. Three different variants of the central domain of PvCSP are described: VK210, VK247, and P. vivax-like [9-11]. These three variants present worldwide distribution and can be identified by both serological and molecular methods [12-15]. Antibodies directed against the PvCSP central repeats domain can neutralize the sporozoite infectivity, allowing for the acquisition of sterile protection [16]. A VLP formulation containing PvCSP-based antigens (VK210 and VK247) combined with HBsAg showed promising results both alone and in combination with other antigens $[17,18]$. However, other studies have demonstrated the importance of the three alleles in conferring worldwide protection against $P$. vivax malaria based on the newly developed CSP-based vaccine [19].

The only vaccine formulation against $P$. vivax malaria tested in phase $\mathrm{I} / \mathrm{II}$ a clinical trials so far, VMP001/AS01B, contains the repeat sequences of VK210 (nine repeats) and VK247 (one repeat) fused to $\mathrm{N}$ - and C-terminal conserved regions of PvCSP. This recombinant protein has shown the ability to induce a potent immune response in malaria-naïve, healthy volunteers. This vaccine does not induce sterile protection against $P$. vivax in any of the volunteers. However, $59 \%$ of the vaccinees presented a significant time delay in the development of parasitemia as compared to the control group [20].

In addition to the conserved domains, our research group has developed recombinant vaccine formulations targeting all three variants of $P$. vivax CSP capable of eliciting immune responses in mice in the last few years [21]. These constructs have been expressed in both prokaryotic [21] and eukaryotic (yeast) systems [22,23]. The recombinant protein PvCSP-All CT $_{\text {has }}$ been found to be highly immunogenic in mice when administered with Poly (I:C) adjuvant. When challenged with a transgenic parasite $(\mathrm{Pb} / \mathrm{PvVK} 210), 4 / 6$ mice demonstrated protective immune responses. In comparison to the controls, the immunized group displayed a 20-fold reduction in the liver parasite burden [22].

VLPs are known for their intrinsic "self-assembling" capability and their ability to induce a much stronger stimulation of B- and T-cell-mediated immune responses [23]. Therefore, the use of VLPs in vaccine formulations has been extensively studied. Although these molecular structures resemble whole virus particles, they do not have genetic material and are therefore unable to infect cells and self-replicate, making them a very safe choice for vaccine formulations [24]. Additionally, VLPs are known for their efficiency at presenting heterologous target antigens-a strategy that can radically alter the magnitude of the immune response, thereby significantly improving the protection that the new vaccines confer [25-27]. 
The VLP advantages are widely known despite technical difficulties such as yield, purification, and storage of these particles for the development of new vaccines [28]. Memory immune response against the viral particle is another concerning matter when considering VLPs as vaccine platforms [29].

Therefore, our study aimed to overcome these issues by fusing the vaccine antigens to a core viral protein rather than the surface proteins (characteristic of VLPs). For this, we used the mumps viral nucleocapsid protein (NP) in our formulation due to its ability to form stable nucleocapsid-like particles (NLPs) when expressed by the P. pastoris expression system [30]. In addition, this protein showed low seroprevalence in mumps-vaccinated individuals [31].

In this study, NLPs were formed by fusing two chimeric proteins containing the PvCSP sequences to the mumps-NP sequence as a vaccine candidate to elicit stronger immune responses in terms of magnitude and breadth. This strategy provided enhanced protection in mice against a malarial challenge with a transgenic $\mathrm{Pb} / \mathrm{PvVK} 210$ parasite.

\section{Materials and Methods}

\subsection{Generation of Recombinant NLP-Fused Proteins}

The gene sequences encoding recombinant PvCSP proteins NLP-CSP $\mathrm{CT}_{\text {and }}$ NLP-CSP $\mathrm{R}_{\mathrm{R}}$ were synthesized using codon optimization for expression in P. pastoris (GenScript, Piscataway, NJ, USA). Both proteins contained the three variant tandem repeats domains of PvCSP [22] fused with the mumps virus nucleocapsid protein (UniProtKB/Swiss-Prot: AFO62160) sequence. The NLP-CSP ${ }_{\mathrm{CT}}$ protein also contained the conserved C-terminal of PvCSP following the repeats domains. The mumps virus NP sequence was associated with the sequences of PvCSP using an amino acid linker (GAAGAGA) [32]. The sequences described above were cloned into the restriction sites EcoRI and NotI of the plasmid pPIC9K (Invitrogen, Life Technologies Corporation USA Inc., Waltham, MA, USA). In accordance with a previous study, this enabled the secretion and expression of the proteins under control of the alcohol oxidase gene promoter (AOX1). Additionally, both recombinant proteins contained a hexa-histidine tag at the C-terminus end, enabling further purification by Nickel Resin Affinity Chromatography. To avoid N-glycosylation, the sequences were analyzed with the NetNGlyc 1.0 server (DTU Health Tech, Technical University of Denmark) and three putative N-linked glycosylation (NxS/T) sites found were replaced by the following amino acids ( $\mathrm{NxS} / \mathrm{T}$ to $\mathrm{AxS} / \mathrm{T})$.

\subsection{Transformation of P. pastoris Host Strains}

The P. pastoris strain GS115 (his4) (Invitrogen, Life Technologies Corporation USA Inc., Waltham, MA, USA) was transformed by electroporation using linearized plasmids treated with Sal I (New England Biolabs Inc., Ipswich, MA, USA). The transformed yeast was then grown on histidine-deficient media for the selection of the His ${ }^{+}$clones. According to the instructions of the Pichia Expression Kit from Invitrogen, the selection of clones with multiple inserts was carried out on YPD (Yeast extract - Peptone - Dextrose) plates containing geneticin (Sigma-Aldrich, St. Louis, MO, USA) (from 0.25 to $4.0 \mathrm{mg} / \mathrm{mL}$ ).

\subsection{Production of PvCSP}

The selected clones were grown for $24 \mathrm{~h}$ at $30{ }^{\circ} \mathrm{C}$ with constant stirring ( $\left.230 \mathrm{rpm}\right)$ in $40-200 \mathrm{~mL}$ of medium containing $1 \%$ glycerol (BMGY) to enable expression of the recombinant proteins. The cells were then harvested by centrifugation, solubilized in 40-200 mL of medium containing $1 \%$ methanol (BMMY), and cultured at $28^{\circ} \mathrm{C}$ with constant stirring (230 rpm). Induction was maintained by the daily addition of $1 \%$ methanol throughout the incubation period of 72-96 h. The cells were harvested by centrifugation, and the supernatant was filtered out using $0.45 \mu \mathrm{m}$ membranes (Merck Millipore, Billerica, MA, USA). 


\subsection{Purification of Recombinant Proteins}

The purification of the recombinant proteins was performed in a two-step procedure (affinity and ion exchange chromatographies). Initially, the supernatant containing the solubilized protein was subjected to affinity chromatography using a HisTrap ${ }^{\mathrm{TM}}$ FF nickel (GE Healthcare USA Inc., Pittsburgh, PA, USA) column coupled to the FPLC ÄKTA prime plus (GE Healthcare USA Inc., Pittsburgh, PA, USA) system. Elution occurred against an imidazole gradient (15-400 mM, USB, Affymetrix USA Inc., Santa Clara, CA, USA) in a phosphate-chloride buffer $\left(20 \mathrm{mM} \mathrm{NaH}_{2} \mathrm{PO}_{4}\right.$ (Synth, Labsynth Products for Laboratories BRA Ltda., Diadema, Brazil) $20 \mathrm{mM} \mathrm{Na}_{2} \mathrm{HPO}_{4}$ (Synth, Labsynth Products for Laboratories BRA Ltda.), and 0.5 M NaCl (Synth, Labsynth Products for Laboratories BRA Ltda.), $\mathrm{pH}=6.0$ ).

Fractions containing the recombinant proteins, identified on 12\% SDS-PAGE gels stained with Coomassie blue solution, were dialyzed on 10,000 MWCO SnakeSkin Pleated Dialysis Tubing membrane (Thermo Fisher Scientific USA Inc., Waltham, MA, USA) against $20 \mathrm{mM}$ Tris-HCl, $(\mathrm{pH}=8.0)$. After dialysis, the proteins were filtered $(0.45 \mu \mathrm{m})$ and subjected to a purification step by ion exchange chromatography using the HiTrap ${ }^{\mathrm{TM}}$ QFF Column (GE Healthcare USA Inc.), also coupled to the ÄKTA system. Protein elution occurred in a linear gradient from 0 to $1 \mathrm{M} \mathrm{NaCl}$ over $20 \mathrm{mM}$ Tris- $\mathrm{HCl}$ buffer (Invitrogen, Life Technologies Corporation USA Inc., Waltham, MA, USA). Fractions containing the chimeric recombinant proteins were then dialyzed against phosphate-buffered saline (PBS) (8 mM $\mathrm{NaH}_{2} \mathrm{PO}_{4}, 2.3 \mathrm{mM} \mathrm{Na}_{2} \mathrm{HPO}_{4}, 130 \mathrm{mM} \mathrm{NaCl}, \mathrm{pH}=7.4$ ) overnight, with constant stirring at $4{ }^{\circ} \mathrm{C}$.

Protein concentration was determined by densitometry analysis using ImageQuant ${ }^{\mathrm{TM}} \mathrm{TL}$ version 8.1 software (GE Healthcare USA Inc.) and compared to a calibration curve with defined concentrations of bovine serum albumin (BSA, Invitrogen, Life Technologies Corporation USA Inc.).

\subsection{Transmission Electron Microscopy}

The purified proteins NLP-CSP ${ }_{\mathrm{CT}}$ and NLP-CSP $\mathrm{R}_{\mathrm{R}}$ were diluted to the concentration of $2 \mu \mathrm{g} / \mathrm{mL}$ and placed in Formvar/carbon-coated electron microscopy grids (EMS \# FCFT200-Cu). The grids were covered and incubated for $20 \mathrm{~min}$ in a dry environment. The lower grids were washed for $2 \mathrm{~min}$ in distilled water, then in 1\% glutaraldehyde (Sigma-Aldrich \# G5882) for 5 min and again in water for $2 \mathrm{~min}$. These steps were repeated 7 times. Then, the grids were placed in $50 \mu \mathrm{L}$ of $4 \%$ uranyl acetate (EMS, \# 22400) for $7 \mathrm{~min}$. The grids were examined the next day under a transmission electron microscope, Tecnai FEI G20 200 kV, at the Microscopy Center in the Department of Development and Cell Biology at the Biomedical Sciences Institute of the University of São Paulo, under the supervision of Professor Ii-Sei Watanabe.

\subsection{Immunoblot Assay}

The recombinant proteins NLP-CSP CT $_{\text {and }}$ NLP-CSP ${ }_{R}$ were electrophoresed using 12\% SDS-PAGE gel and, thereafter, electrotransferred onto Hybond $\mathrm{N}$ nitrocellulose membranes (GE Healthcare USA Inc.). For the protein transfer, a transfer buffer (160 mM glycine, $25 \mathrm{mM}$ Tris, and 20\% (v/v) methanol) was used, and the reaction occurred at $90 \mathrm{~V}$ for $30 \mathrm{~min}$ using the Bio-Rad semi-wet transfer system (Bio-Rad Laboratories USA Inc., Hercules, CA, USA). The membranes were stained with Ponceau-S solution (0.1\% Ponceau red (Bio-Rad Laboratories USA Inc.) and 10\% acetic acid) and then incubated for $16-18 \mathrm{~h}$ at $4{ }^{\circ} \mathrm{C}$ with a blocking solution (5\% skimmed milk (Molico®, Nestlé S.A., Vevey, VD, Switzerland), 2.5\% (w/v) bovine serum albumin (Sigma-Aldrich, St. Louis, MO, USA) in PBS). The membranes were then incubated for $1 \mathrm{~h}$ at room temperature (RT) with an individual primary antibody (anti-PvCSP-VK210 (2F2), anti-PvCSP-VK247 (2E10.E9) or anti-mumps-NP (7B10) (Abcam; Ab9880) monoclonal antibodies (mAbs)) at a dilution of 1:2000 (v/v) and a polyclonal anti-P. vivax-like antibody [22] at a dilution of 1:2000 (v/v). After 3 washings of 10 min each with PBS-T ((0.05\% Tween 20 (v/v), Invitrogen, Life Technologies Corporation USA Inc.), the membrane was incubated with a peroxidase-conjugated anti-mouse IgG antibody (KPL, Kirkegaard \& Perry 
Laboratories USA Inc., Gaithersburg, MA, USA) diluted 1:3000 in blocking solution for $1 \mathrm{~h}$ at RT. After 3 washing steps with PBS-T, the membrane was developed using the SuperSignal kit (Thermo Fisher)

\subsection{High-Performance Reverse-Phase Liquid Chromatography (RP-HPLC)}

The purified recombinant NLP-CSP ${ }_{C T}$ and NLP-CSP $P_{R}$ proteins were analyzed through high-performance reversed-phase liquid chromatography (RP-HPLC) using a Vydac C4 column $(4.6 \mathrm{~mm} \times 250 \mathrm{~mm}$, for particles of $300 \mathrm{Hm}$ ) in a Shimadzu LC Solution HPLC system (Shimadzu JPN Corp., Kyoto, KY, USA). The technique was performed at the Laboratory of Toxins and Natural Products of Algae (School of Pharmaceutical Sciences, University of São Paulo). A 05-100\% acetonitrile (Merck KGaA DEU Inc.) gradient comprising $90 \%$ acetonitrile with $0.1 \%$ trifluoroacetic acid (TFA, Thermo Fisher Scientific USA Inc.) was used at approximately $24{ }^{\circ} \mathrm{C}$ under a flow of $1 \mathrm{~mL} / \mathrm{min}$ for $40 \mathrm{~min}$. The elution was monitored with a UV-Visible Absorbance Detector (Shimadzu SPD M20A, Shimadzu JPN Corp., Kyoto, Japan) at $214 \mathrm{~nm}$.

\subsection{Circular Dichroism}

The circular dichroism (CD) tests were carried out on the JASCO-J810 spectropolarimeter (Jasco ITA Corp., Milano, MI, Italy) equipped with a continuous temperature control system (Central Analytical Laboratory, School of Pharmaceutical Sciences, University of São Paulo). The recombinant NLP-CSP ${ }_{C T}$ and NLP-CSP $\mathrm{R}_{\mathrm{R}}$ proteins were loaded in a $5 \mathrm{~mm}$ quartz cuvette and underwent $8 \mathrm{UV}$ scans at a speed of $20 \mathrm{~nm} / \mathrm{min}$. These scans were performed at $260-200 \mathrm{~nm}$ with bandwidth/response time being $1 \mathrm{~nm} / 1$ second at $20^{\circ} \mathrm{C}$. The spectra were corrected by subtracting the buffer signal (PBS), while the molar ellipticity $(\theta)$ was calculated for the prediction of the secondary structures of the recombinant proteins using the CDNN Secondary Structure Analysis software (Applied Photophysics GBR Ltd., Leatherhead, $\mathrm{Su}, \mathrm{UK})$.

\subsection{Mice Immunization}

Six- to eight-week-old female C57BL/6 mice were purchased from the animal facility of the School of Pharmaceutical Sciences/Chemistry Institute (University of Sao Paulo). All animal experiments were approved by the Animal Care and Use Committee of the University of São Paulo (CEUA/FCF 74.2016-P531). Briefly, mice were subcutaneously (s.c.) immunized 3 times with the vaccine formulation of recombinant protein/adjuvant. For each dose, a final volume of $100 \mu \mathrm{L}(10 \mu \mathrm{g}$ of protein/sterile PBS/50 $\mu$ g of Poly (I:C) HMW (Polyinosinic-polycytidylic acid - High Molecular Weight) (Invitrogen, Life Technologies Corporation USA Inc., Waltham, MA, USA) was injected over the flank per mouse.

\subsection{Antibody Measurement}

For immunological assays, 14 days after each immunization, blood was collected from the submandibular vein ( $n=6$ mice per group). Sera were analyzed for the presence of antibodies against each PvCSP variant as well as N- and C-terminal regions of the PvCSP. Antibodies were detected through an enzyme-linked immunosorbent assay (ELISA), as previously described [21]. The recombinant proteins FliC-VK210, FliC-VK247, and FliC-P. vivax-like [33] were used as target antigens (200 ng/well). Following overnight incubation at RT, the plates were washed with a solution of PBS 0.05\% Tween-20 (PBS-T) and blocked with a blocking solution (PBS, $5 \%(\mathrm{w} / \mathrm{v})$ skimmed milk) for $2 \mathrm{~h}$ at $37^{\circ} \mathrm{C}$. Serial dilutions starting with 1:200 of murine polyclonal sera were added to the wells and incubated for $1 \mathrm{~h}$ at RT. After a washing step with PBS-T, peroxidase-labeled goat anti-mouse IgG (Sigma, St. Louis, MO, USA) was added to each well at a 1:3000 dilution. The OPD/acid stop system was then used to determine anti-PvCSP titers based on the highest dilution of sera yielding an $\mathrm{A}_{492}$ value higher than 0.1 [22].

The EUROIMMUN anti-mumps-virus ELISA (IgG) assays (EI 2630-9601 G) were used to determine the mumps antibody seroprevalence. Positive and negative controls along with calibrators for 
semi-quantitative calculation and sample preparation was used according to the manufacturer's instructions. The cut-off values for the anti-mumps-virus ELISA and NP ELISA were as follows: negative $<0.30$; borderline $\geq 0.30-0.42$; positive $\geq 0.42$. The recombinant protein Mumps-NP (Abcam; ab74560) was used as the target antigen (200 ng/well) in an ELISA performed to determine the titers of the mumps virus nucleoprotein-specific antibodies. We assayed serum samples collected from 80 individuals living in different malaria-endemic areas in the north of Brazil (40 P. vivax-infected and 40 non-infected) [34]. We also assayed 12 samples from individuals who were immunized or had mumps living in non-endemic areas.

\subsection{Antibody Secreting B-Cell Measurement by ELISPOT}

For antibody-secreting cell (ASCs) measurement, a second group of mice was immunized as described above ( $n=4$ mice per group). We performed the ELISPOT assays as previously described by Fabris et al. [35]. Briefly, ELISPOT plates (Millipore; MSHAN4B50) were coated with $1 \mu \mathrm{g} / \mathrm{mL} \mathrm{of}$ recombinant proteins overnight at $4{ }^{\circ} \mathrm{C}$ to identify PvCSP-specific ASCs. Plates were washed 4 times with PBS 0.05\% Tween 20 (PBS-T) and 4 times with PBS and blocked for $2 \mathrm{~h}$ at $37^{\circ} \mathrm{C}$ with RPMI medium supplemented with 10\% FBS (R10 medium). Splenocytes and bone marrow cells were isolated, counted, and plated in serial 3-fold dilutions in R10 medium. ELISPOT plates were incubated overnight in a 5\% $\mathrm{CO}_{2}$ incubator at $37^{\circ} \mathrm{C}$. Plates were washed 4 times with PBS and 4 times with PBS-T, followed by incubation with anti-mouse IgG-biotin conjugated antibodies (BD), diluted 1:1000 in PBS-0.05\% Tween 20 containing $2 \%$ FBS solution (PBS-T-F) for 90 min at RT. Wells were again washed 4 times with PBS-T before the addition of Avidin D-HRP (KPL) diluted 1:3000 in PBS-T-F. After a 3-h incubation at RT, plates were washed 4 times with PBS-T and 4 times with PBS. Spots were developed with filtered 3-amino 9-ethylcarbazole (AEC) substrate as recommended by the manufacturer (BD). To stop the reaction, wells were washed with running water and plates were dried before spot counting. Images of spots were defined by an automated stereomicroscope (KS ELISPOT, Zeiss, Oberkochem, Germany).

\subsection{Parasites, Mice, and Mosquitoes}

Sporozoites (spz) from Plasmodium berghei ANKA expressing P. vivax CSP VK210 repeats (Pb/PvVK210) were obtained as previously described [36]. C57BL/6JRj mice were purchased from Janvier Labs. All animal experiments were approved by the Animal Care and Use Committee of Institut Pasteur (CETEA Institut Pasteur 2013-0093, Ministère de 1'Enseignement Supérieur et de la Recherche MESR 01324) and were performed in accordance with European guidelines and regulations (directive 2010/63/EU). For all tests, 6- to 8-week-old females were used and allocated randomly to cages. Two independent immunization/blind challenge experiments were performed using 7 animals per experiment, as described previously [37].

Anopheles stephensi mosquitoes (SDA500 strain) were reared at the Centre for Production and Infection of Anopheles (CEPIA) at the Institut Pasteur using standard procedures. For the production of rodent Plasmodium spp. spzs, mosquitoes were fed on infected RjOrl:SWISS mice 1-2 days after emergence and kept in a humidified chamber at $21^{\circ} \mathrm{C}$. One week after infection, Pb/PvVK210-infected mosquitoes were fed on naïve RjOrl:SWISS mice. For footpad injections, Pb/PvVK210 spzs were collected from mosquito-infected salivary glands 21-28 days after the infectious blood meal [37].

\subsection{Murine Sporozoite Challenge}

Transgenic Pb/PvVK210 spz were maintained in female A. stephensi mosquitoes. The total number of spz was determined using a Kova glass slide; $5000 \mathrm{spz} / \mu \mathrm{L}$ of PBS were microinjected in the footpad skin using a 35-36 g needle with a NanoFil syringe (World Precision Instruments, Sarasota, FL, USA) in control and immunized mice [37]. Parasitemia was determined by flow cytometry, performed during days 4-10 after the spz challenge. For this, 200,000 erythrocytes were examined for each sample. A quantitative analysis of protection was performed using the parasitemia log values on day 5 post-infection, when the blood parasites were still exponentially growing [37]. 


\subsection{Statistical Analyses}

One-way analysis of variance (ANOVA) and Tukey's honestly significant difference (HSD) test were used to compare the results from different groups. Differences were considered statistically significant when $p<0.05$. In the challenge experiments, the significant protection was determined using Fisher's exact test.

\subsection{Data Availability}

The data that support the findings of this study are available from the corresponding author upon reasonable request.

\section{Results}

\subsection{Generation, purification, and recognition by $m A$ bs of the proteins $N L P-C S P_{C T}$ and $N L P-C S P_{R}$}

We started our study by designing the NLP-CSP ${ }_{\mathrm{CT}}$ and NLP-CSP $\mathrm{R}_{\mathrm{R}}$ constructs. Codon-optimized genes were synthesized containing the same coding regions for the Mumps-NP, 7 amino acid linker (GAAGAGA), and hexa-histidine tag for both constructs. However, their PvCSP sequences were distinct. While the NLP-CSP ${ }_{\mathrm{CT}}$ protein had the Mumps-NP sequence, linker, and PvCSP-All $\mathrm{CT}$ sequences (RI region from $\mathrm{N}$-terminal domain, representative sequences of the three amino acid repeat variants and the C-terminal domain of the PvCSP protein [22] and his-tag), the NLP-CSP $P_{R}$ protein comprised the Mumps-NP sequence, linker, PvCSP RI region, and repeat variants (Figure 1a). Recombinant proteins were produced and purified as described and separated by SDS-PAGE under reducing conditions (Figure $1 \mathrm{~b}$ ).

To determine whether the produced polypeptides retained the epitopes recognized by specific mAbs generated against radiation-attenuated $P$. vivax sporozoites, we performed an immunoblot analysis. As depicted in Figure $1 \mathrm{~b}$, purified proteins were recognized by specific $\mathrm{mAbs}$ generated against radiation-attenuated $P$. vivax sporozoites (mAb VK210 2F2 and mAb VK247 2E10.E9), as well as polyclonal anti-P. vivax-like antibodies [22] and anti-mumps nucleoprotein antibody (mAb 7B10). After chromatographic separation, the purity of each protein was analyzed by RP-HPLC. Chromatograms revealed a high degree of purity for both recombinant proteins (Figure 1c).

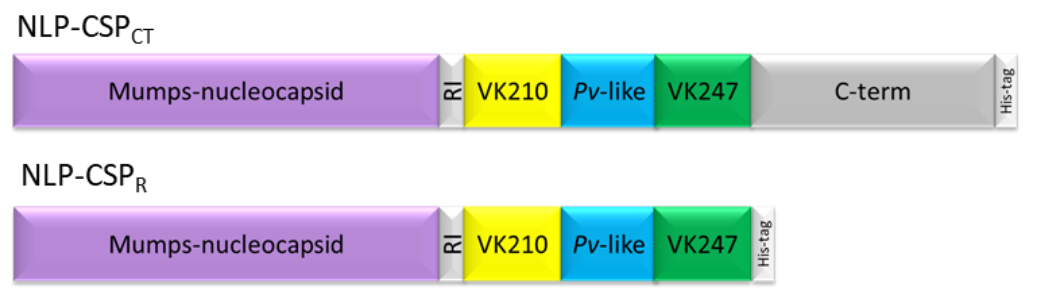

(a)
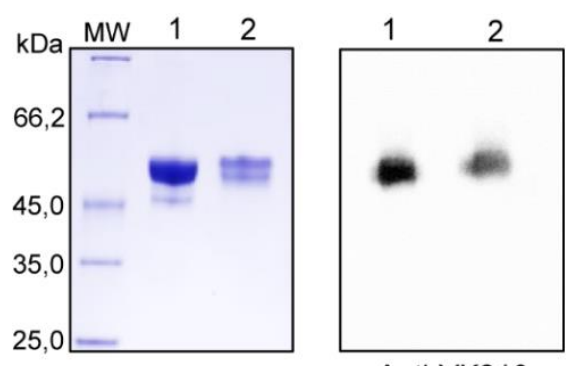

Anti-VK210

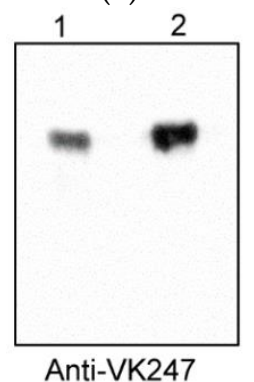

(b)

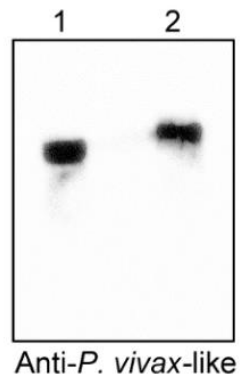

Anti- $P$. vivax-like

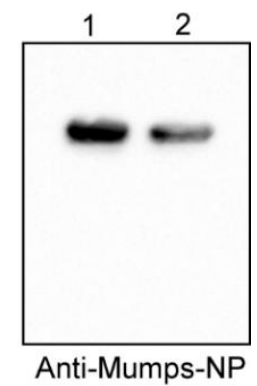

Anti-Mumps-NP

Figure 1. Cont. 

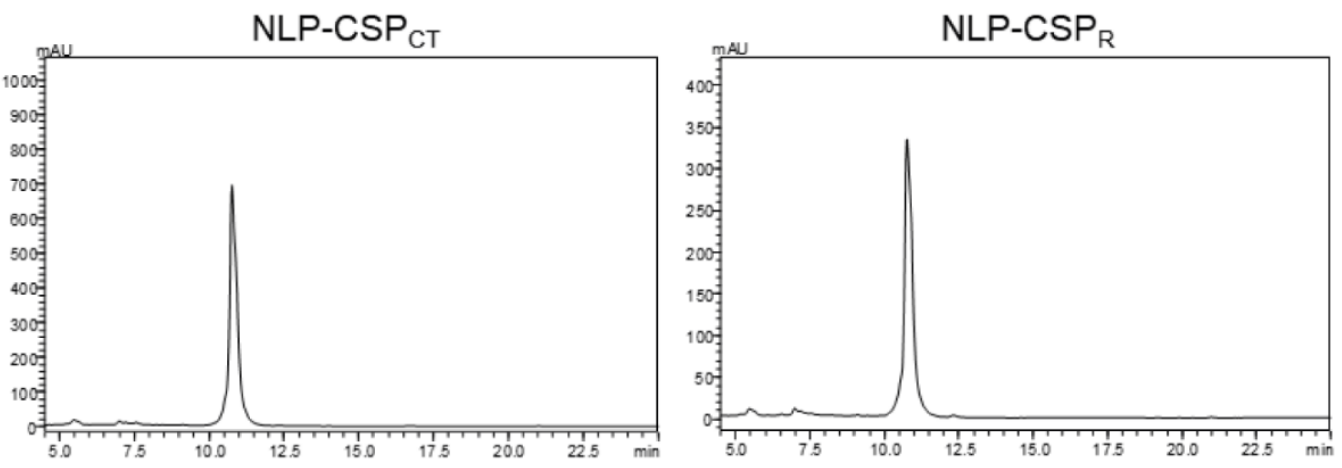

(c)

Figure 1. Generation, purification, and $\mathrm{MAb}$ recognition of nucleocapsid-like particles (NLP)-recombinant proteins. (a) Schematic representation of P. vivax circumsporozoite (PvCSP) proteins fused with mumps virus nucleocapsid expressed from P. pastoris. (b) NLP-CSP $\mathrm{CT}_{\text {and }}$ $\mathrm{NLP}_{-} \mathrm{CSP}_{\mathrm{R}}$ are represented as lines 1 and 2, respectively. SDS-PAGE analysis under reducing conditions of purified recombinant proteins gel-stained with Coomassie blue $(1 \mu \mathrm{g}$ of protein per lane) and protein recognition by $\mathrm{mAbs}$ anti-VK210, anti-VK247, and anti-NP, and by polyclonal anti-P. vivax-like antibody. (c) The purity of the proteins after chromatography was analyzed by RP-HPLC, in which the gradient elution was developed by combining $0.1 \%$ trifluoroacetic acid (TFA) in water and $0.1 \%$ TFA in $90 \%$ acetonitrile at $24{ }^{\circ} \mathrm{C}, 1 \mathrm{~mL} / \mathrm{min}$ for $40 \mathrm{~min}$ in a C18 column.

\subsection{Preliminary Structural Characterization of the Proteins $N L P-C S P_{C T}$ and $N L P-C S P_{R}$}

The secondary structures of the recombinant proteins were analyzed using far-UV CD spectroscopy. The CD spectra of the two proteins (Figure 2a) showed negative bands near 222 and $208 \mathrm{~nm}$, consistent with random coiled proteins.

The following estimated percentages of $\alpha$-helix, $\beta$-sheet, and $\beta$-turn for each protein were predicted: (i) NLP-CSP ${ }_{\mathrm{CT}}$ : $12.4 \% \alpha$-helix, $20.7 \%$ anti-parallel $\beta$-sheet, 19.5\% parallel $\beta$-sheet, $22.4 \%$ $\beta$-turn; (ii) NLP-CSP $P_{R}: 12.4 \% \alpha$-helix, 20.7\% anti-parallel $\beta$-sheet, $19.6 \%$ parallel $\beta$-sheet, $22.5 \% \beta$-turn. However, the differences in the spectra patterns near $200 \mathrm{~nm}$ indicated a higher stability of NLP-CSP $\mathrm{CT}_{\text {. }}$.

The electron microscopy (EM) examination of purified NLP proteins revealed large quantities of circular structures, which displayed some features common to VLPs (Figure 2b). These circular structures appeared as flexible forms $15-20 \mathrm{~nm}$ in diameter. Formation of NLPs in yeast expression systems occurred in the absence of other viral proteins, as previously described [30].
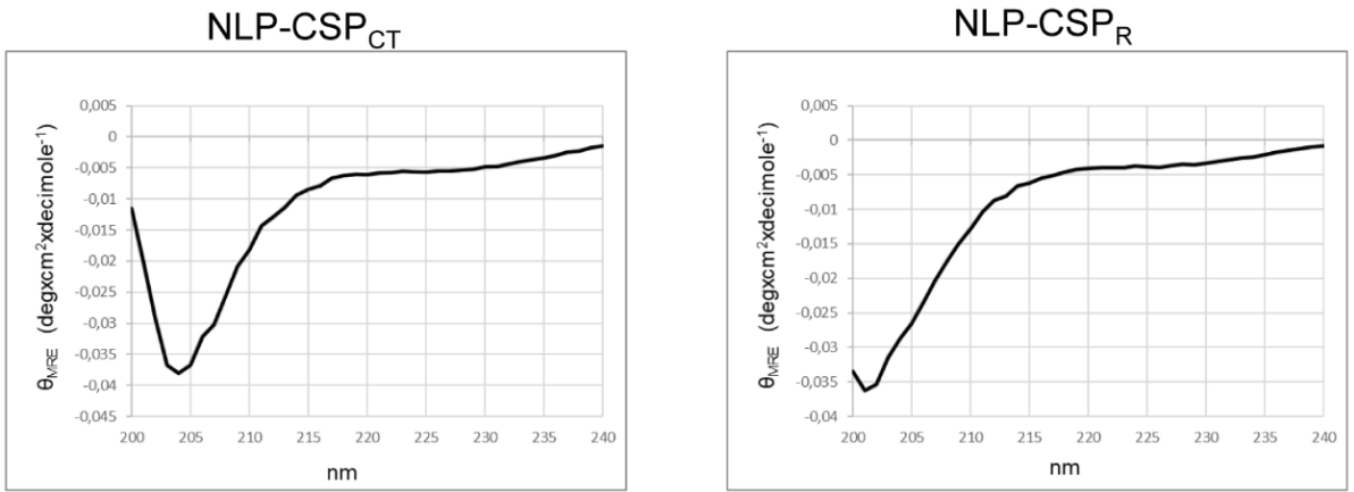

(a)

Figure 2. Cont. 

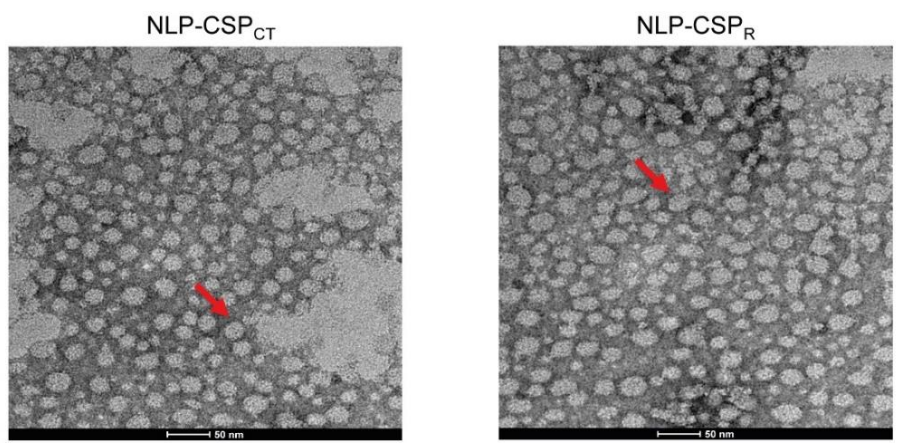

(b)

Figure 2. Structural characterization of NLP-recombinant proteins. (a) The secondary structure of NLP-CSP $_{C T}$ and NLP-CSP $R$ was analyzed by circular dichroism (CD) spectrum. The CD spectrum of the recombinant proteins was recorded from 190 to $260 \mathrm{~nm}$ using a JASCO-J815 spectropolarimeter. (b) The NLP-CSP ${ }_{\mathrm{CT}}$ and NLP-CSP $\mathrm{R}_{\mathrm{R}}$ proteins were negatively stained with $0.5 \%$ uranyl acetate and visualized by Transmission Electron Microscopy (TEM).

\subsection{Seroprevalence of Antibodies Specific to the Mumps Virus and Its Nucleoprotein in Residents of Malaria-Endemic and Non-Endemic Areas}

Before the further assessment of NLP-CSP ${ }_{\mathrm{CT}}$ immunogenicity, the seroprevalence of antibodies specific to the mumps virus was investigated. Considering the presence of the mumps viral antigen in the described malaria vaccine formulations, this analysis is necessary. Any immunological memory against the mumps virus in the general population (generated by vaccination or natural exposure) could interfere with the immune response against PvCSP as demonstrated with other formulations [29]. Therefore, we measured the serum antibodies specific to the mumps virus and its NP in individuals from malaria-endemic and non-endemic areas. While most of the subjects tested mumps-positive, demonstrating that most of them had been vaccinated against mumps, the subjects were negative for Mumps-NP $(p<0.0001)$ regardless of the area of origin or any previous exposure to malaria (Figure 3 ). This result is in agreement with the low seroprevalence of antibodies specific to Mumps-NP reported previously [31].

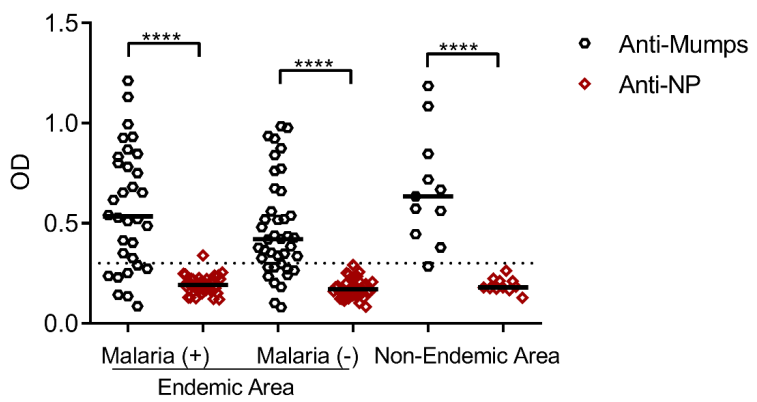

Figure 3. Comparison of antibody response against the mumps virus and nucleocapsid proteins (NPs). The serology of $P$. vivax-infected individuals $(n=40)$, non-infected individuals $(n=40)$, and individuals who were immunized or had mumps from a non-endemic $P$. vivax area $(n=12)$ was investigated using a commercial ELISA kit. The dashed line in the chart indicates the minimum threshold $(\mathrm{OD}=0.3)$ for considering an individual to be immunized against the mumps virus, as indicated in the supplier's manual. The results were statistically compared using one-way ANOVA followed by Tukey's test. Significant differences between groups are denoted on the graph: ${ }^{*} p<0.05,{ }^{* *} p<0.01,{ }^{* * *} p<0.001$, and ${ }^{* * *} p<0.0001$. Non-significant (ns) differences are indicated $(p>0.05)$.

\subsection{Antibody Responses in Mice Vaccinated with NLP-CSP $C T$ and NLP-CSP}

The immunogenicity of the recombinant proteins was assessed after their in vivo administration in conjugation with Poly (I:C), a synthetic analog of double-stranded RNA (dsRNA) agonist of 
TLR3 [38] in mice. Each animal received three doses of each protein 14 days apart from each other in a homologous prime-boost vaccination regimen (Figure 4a). When the titers of PvCSP-specific IgG subclasses were evaluated in these groups on day 14 after the second boost, the responses differed significantly. Responses against the NLP-CSP ${ }_{\mathrm{CT}}$ protein resulted in predominately IgG1 rather than IgG2c (ratio-6.48), while a balanced ratio between IgG1 and IgG2c was found against NLP-CSP ${ }_{R}$ (ratio: 0.33). When comparing antibody titers of the same subclass, but in the different groups, we observed a significant increase between the $\operatorname{IgG} 2 b(p=0.0279)$ and $\operatorname{IgG} 2 c(p<0.0001)$ (Figure $4 b)$. In addition, we evaluated antibody specificity against the homologous proteins that contain the repeat regions of each PvCSP protein variant (FliC's) [33], Mumps-NP protein, the NLP-CSP ${ }_{\mathrm{R}}$ and NLP-CSP ${ }_{\mathrm{CT}}$ chimeric proteins, and a protein containing the PvCSP non-repeat regions alone (Pv-No repeat) (Figure 4c).

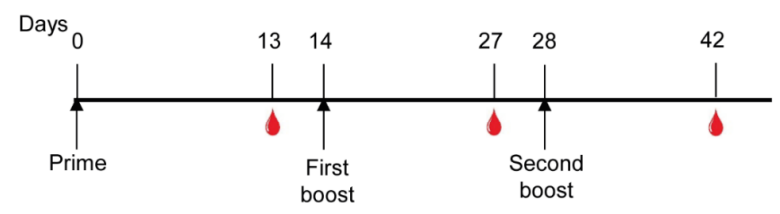

(a)

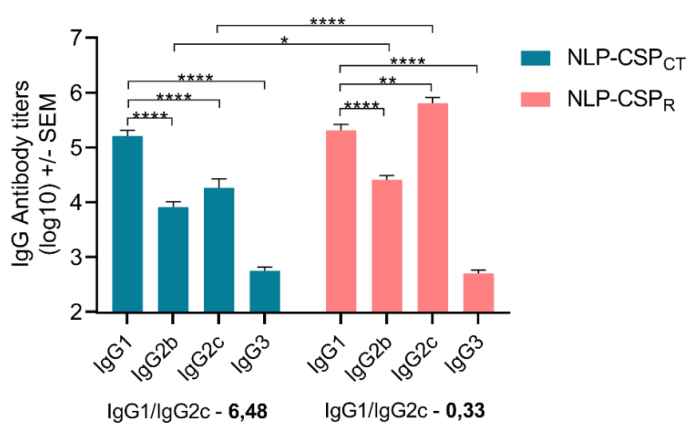

(b)
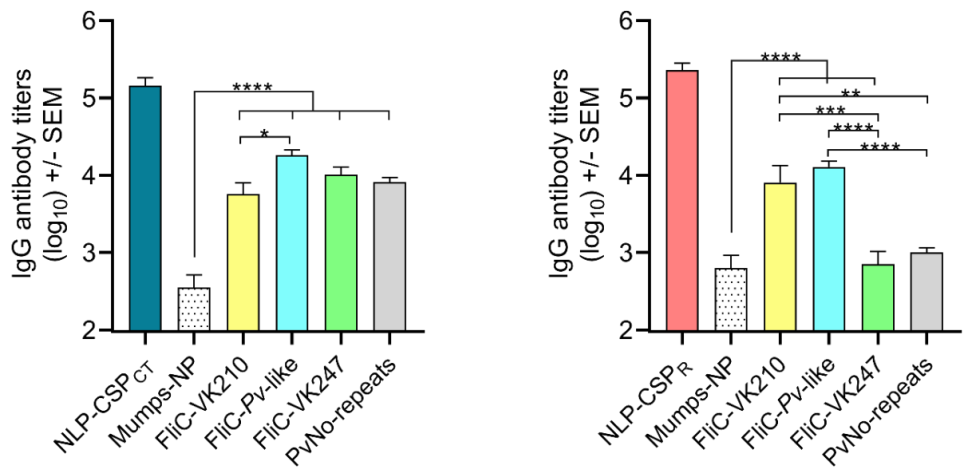

(c)

Figure 4. Specific antibody response in mice immunized with NLPs. (a) Mice immunization schedule: Groups of six C57BL/6 mice were immunized s.c. with three doses 14 days apart with NLPs (10 $\mu \mathrm{g} / \mathrm{dose})$ in the presence of the adjuvant Poly (I:C). The antibody response was then analyzed according to the timeline described. (b) Antibody subclasses against each NLP were analyzed, and the IgG1/IgG2c ratios are expressed below the graph. (c) The elicited Abs specifically recognized the central repeats of the three allelic variants, as shown by the assays for the repeats fused to flagellin FliC (FliC-PvCSP-repeats) or N-C-terminal regions (FliC-No repeats) and Mumps-NP after three doses. All results are expressed as the arithmetic mean titers of each group $\left(\log _{10} \pm \mathrm{SEM}\right)$ and were statistically compared using one-way ANOVA followed by Tukey's test. Significant differences between groups are denoted on the graph: ${ }^{*} p<0.05,{ }^{* *} p<0.01,{ }^{* * *} p<0.001$, and ${ }^{* * *} p<0.0001$. Non-significant (ns) differences are indicated $(p>0.05)$. 
High-antibody titers were measured against homologous proteins (higher than $10^{5}$ ) and each repeat variant, in both groups (higher than $10^{4}$ ), except for $\mathrm{NLP}^{-C_{S P}} \mathrm{R}_{\mathrm{R}}$-vaccinated mice, in which antibody titers for the VK247 variant were significantly lower in comparison to other repeat variants $(p<0.0001$ when compared to $P$. vivax-like and $p=0.0001$ to VK210). The serum from NLP-CSP $\mathrm{CT}_{\text {-vaccinated }}$ mice presented antibody titers for $P$. vivax-like variant that were significantly higher than the VK210 $(p<0.0395)$, but not significant for VK247. Furthermore, mice immunized with NLP-CSP ${ }_{\text {CT }}$ presented antibody titers for the no-repeat variants that were as high as the antibody titers for the repeat variants. Mice vaccinated with NLP-CSP ${ }_{\mathrm{R}}$ presented low antibody titers for no-repeat variants (Figure 4c). As expected, the antibody titer against Mumps-NP protein was significantly lower in comparison to almost all variants in both groups, except for VK247 of the NLP-CSP $\mathrm{R}_{\mathbf{R}}$ group $(p=0.9998)$. These data led to the conclusion that both vaccine formulations induced poor immune responses to Mumps-NP. However, only the vaccine formulation containing NLP-CSP ${ }_{\mathrm{CT}}$ induced high antibody titers to all PvCSP repeat variants and conserved domains. These data and the greater stability of NLP-CSP shown by $\mathrm{CD}$ spectra analyses encouraged the further study of this recombinant protein.

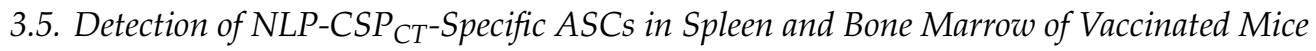

Because we observed high antibody titers to all PvCSP repeat variants in mice immunized with

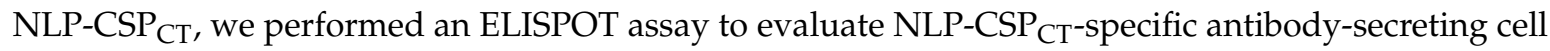
(ASC) generation in the spleen and bone marrow of immunized mice at days 5 and 30, respectively, after the second boost. More specifically, the ELISPOTs were performed against the two chimeric proteins PvCSP-All $\mathrm{CT}$ and NLP-CSP ${ }_{\mathrm{CT}}$, each of the three PvCSP repeat alleles and no-repeat regions, Mumps-NP, and total IgG-secreting cells. We measured ASC frequency in splenocytes 5 days after the second boost, as this is usually the time when their frequency reaches the peak after immunizations [39]. An increased number of ASCs specific to P. vivax-like repeats $(p=0.0097)$, the Pv-No repeats $(p=0.0401)$ portion of the CSP, yPvCSP-All $\mathrm{CT}_{\mathrm{C}}(p=0.0139), \mathrm{NLP}_{\mathrm{CSP}} \mathrm{CT}_{\mathrm{C}}(p=0.0032)$, and Mumps-NP $(p=0.0006)$ was observed in the spleens of immunized mice (Figure 5a,b). However, the number of ASCs specific to VK210 and VK247 was not significantly different from days 0 to 5, nor was the frequency of total IgG secreting cells. By contrast, bone marrow cells were tested for ASCs only 30 days after the second boost, as they take longer to migrate to that location [40]. An augmented frequency of ASCs specific to the two chimeric proteins PvCSP-All ${ }_{\mathrm{CT}}$ and NLP-CSP $\mathrm{CT}_{\mathrm{T}}$ was found in the bone marrow (Figure $5 \mathrm{c}, \mathrm{d}$ ). Although the third dose increased the overall response to the two chimeric proteins, yPvCSP-All $\mathrm{CT}$ $(p=0.0004)$ and NLP-CSP $\mathrm{CT}_{(}(p=0.0031)$, to $P$. vivax-like repeats $(p=0.0278)$ and total $\operatorname{IgG}(p=0.0207)$, no increase in expression was observed in each protein region individually: VK210, VK247, Pv-No repeats, and Mumps-NP. The non-specific responses (total IgG ASCs) were, as expected, the same in both organs regardless of the time after stimuli. The CSP-specific responses accounted for $10 \%$ of the total ASCs in the spleen and bone marrow on days 5 and 30 post-stimuli, respectively (Figure 5e,f).

Therefore, the ELISPOT data correlate with the high antibody titers observed by ELISA in the serum of these mice. The magnitude of the antibody titers presented in the serum was the same as the antibodies secreted by long-lived ASCs present in the bone marrow and newly formed ASCs (briefly present in recirculation and in the secondary lymphoid organs where they are formed, as well as in inflamed tissues for as long as they are inflamed). Because NLP-CSP ${ }_{\mathrm{CT}}$ immunization induces high antibody titers against all PvCSP repeat and non-repeat regions, it may represent the large amount of ASCs generated after the first and second doses that reached the bone marrow. Some ASCs are seen to be formed after the third dose, reflecting in the increased number of ASCs against some portions of the protein seen in the spleen 5 days after the third immunization and in the antibody titers against P. vivax-like, as well as in the increased number of ASCs in the bone marrow 30 days after the third immunization to the whole vaccine protein. 


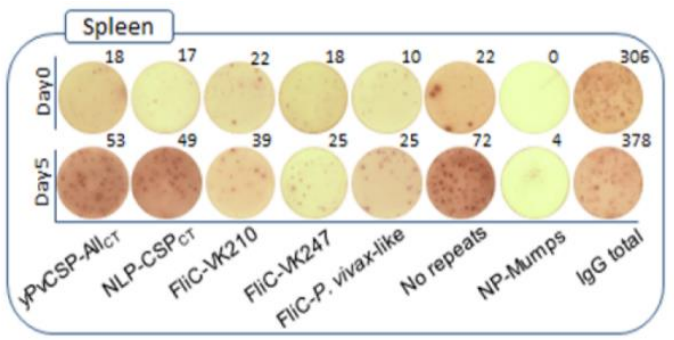

(a)

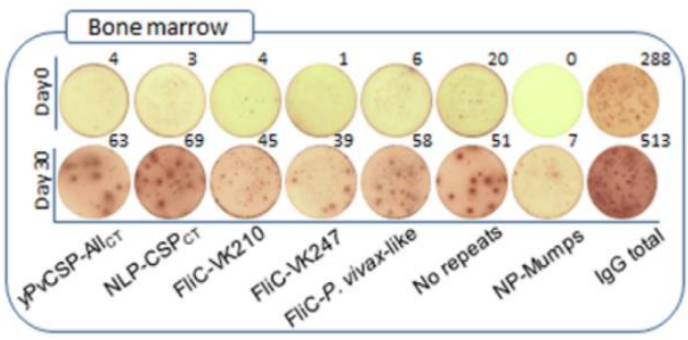

(c)

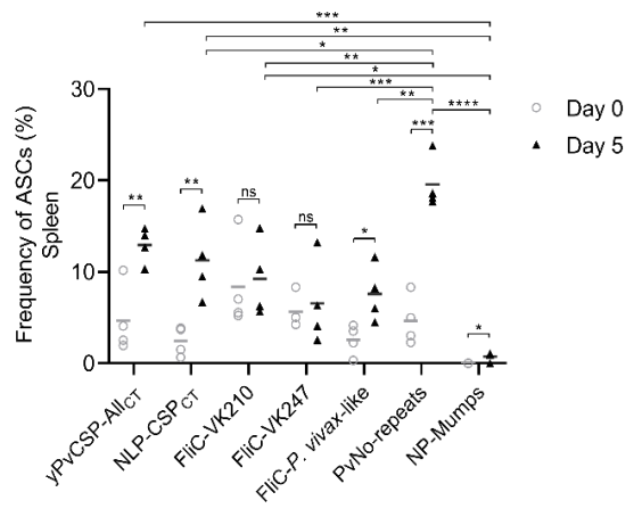

(e)

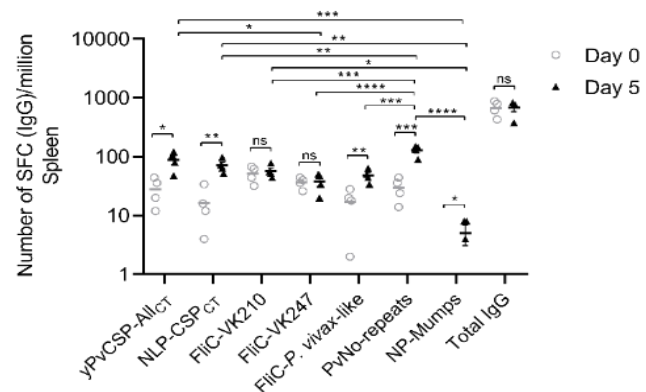

(b)

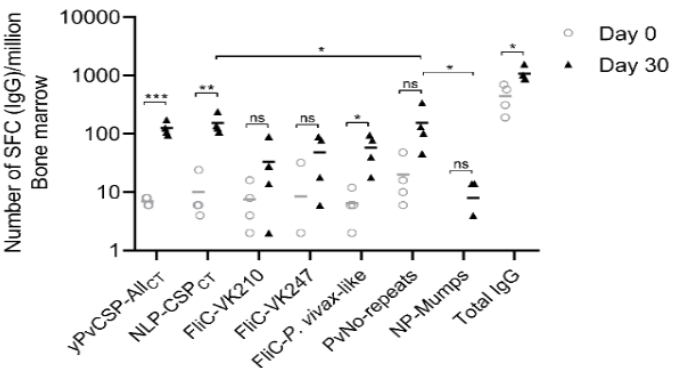

(d)

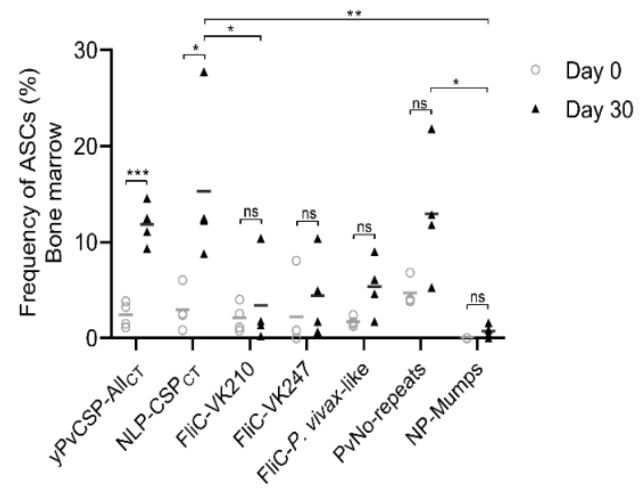

$(\mathbf{f})$

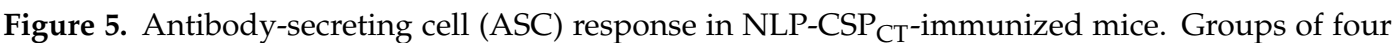

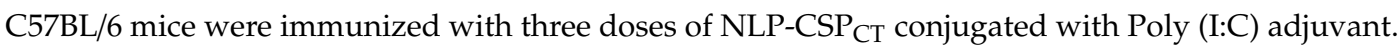
The antigen-specific ASC response in the spleen was measured on days 0 and 5 , and in the bone marrow on days 0 and 30 after the last dose. A representative example of the ASC response specific to

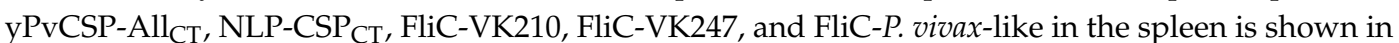
(a), while that of the bone marrow is shown in (c). The wells shown in the figure were plated with $0.5 \times 10^{5}$ cells. The total ASCs were measured for IgG secreting cells specific to the above-mentioned proteins. The data points represent the average ASC counts observed per million cells, while the bars represent the \pm SEM (b and $\mathbf{d}$ ) and frequency (e and $\mathbf{f}$ ). The results were statistically compared using one-way ANOVA followed by Tukey's test. Significant differences between groups are denoted on the graph: ${ }^{*} p<0.05,{ }^{* *} p<0.01,{ }^{* * *} p<0.001$, and ${ }^{* * *} p<0.0001$. Non-significant (ns) differences are indicated $(p>0.05)$. The experiment was performed twice with four mice per group.

\subsection{Assessment of Vaccine Efficacy}

One of the most effective ways to analyze vaccine efficacy is through a challenge test. This approach has been used previously and has proven effective at demonstrating vaccine-induced protection $[21,22,41]$. However, $P$. vivax does not infect rodents. Considering that $P$. berghei is a 
murine-infecting parasite, we used the chimeric parasite $\mathrm{Pb} / \mathrm{PvVK} 210$, in which the repeats of the $\mathrm{PbCSP}$ were replaced by the PvCSP (VK210), as previously described [36]. Thus, mice were immunized 3 times with NLP-CSP ${ }_{\mathrm{CT}}+$ Poly (I:C) or only the adjuvant. Thirty days later, mice were challenged with $5000 \mathrm{~Pb} / \mathrm{PvVK} 210$ sporozoites (Figure 6a). Sterile protection was observed in 2 out of 7 mice until day 10 post-challenge, whereas all control mice were infected by day 4 post-challenge (Figure $6 \mathrm{~b}$ ). In addition to the partial sterilizing protection, a $\sim 10$-fold decrease in parasitemia on day 5 in the

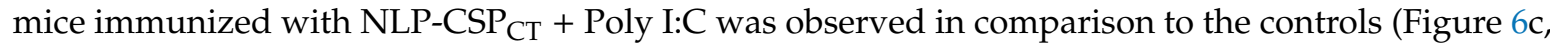
$p=0.0012)$. Moreover, the decrease in parasitemia was still significant in the 5 immunized unprotected mice compared to controls (Figure $6 \mathrm{~d}, p=0.0051$ ).

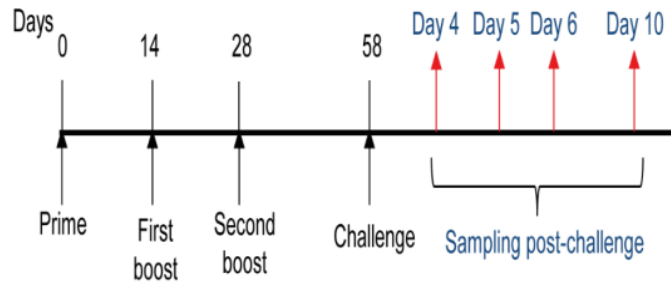

(a)

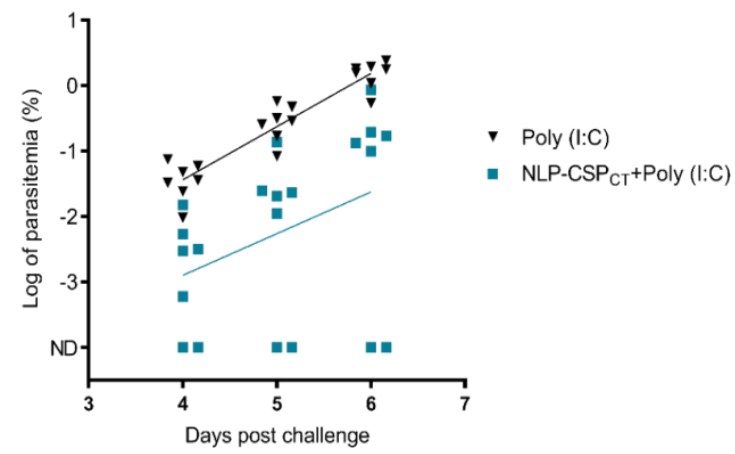

(c)

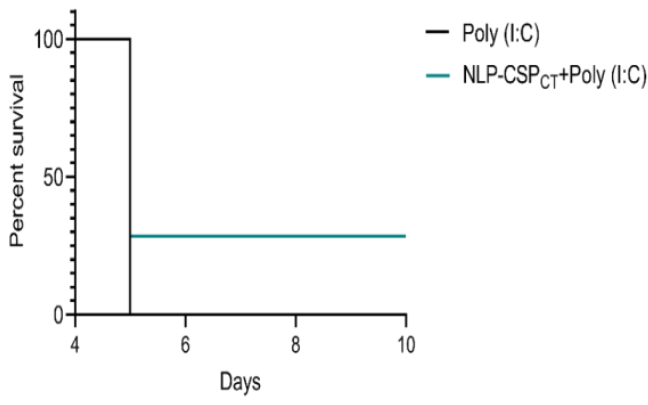

(b)

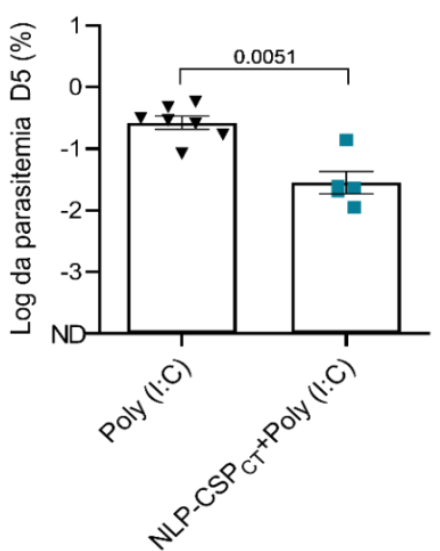

(d)

Figure 6. Evaluation of parasitemia after challenge in mice immunized with a prime-boost regimen. (a) C57BL/6 mice were immunized s.c. with Poly (I:C) or a mixture of Poly (I:C) and $10 \mu \mathrm{g}$ of recombinant

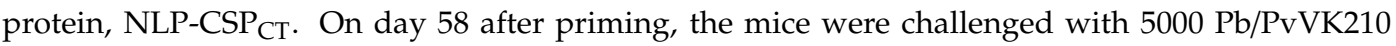
transgenic sporozoites. (b) Surveillance curve with the percentage of non-infected mice in each experimental group is shown. (c) Parasitemia was analyzed by flow cytometry. The percentage of infected red blood cells (iRBCs) on days 4,5 , and 6 post-infection (p.i.) was expressed as log values for normalization before statistical analysis. (d) The log of parasitemia on day 5 (D5) post-challenge was measured in mice in each of the immunized groups. Data from two independent experiments and significance were determined by two-tailed unpaired t-test (Mann-Whitney test).

\section{Discussion}

The use of viral particles as antigen delivery systems has been shown to be an excellent strategy in the development of more efficient vaccines. Some successful cases of commercially available VLP-based vaccines are for Human Papilloma Virus (HPV), such as Cervarix ${ }^{\circledR}$, Gardasil ${ }^{\circledR}$ \& Gardasil9 ${ }^{\circledR}$, and for Hepatitis B Virus (HBV) [42].

We have previously shown that the PvCSP expressed in P. pastoris was highly immunogenic, eliciting antibodies capable of recognizing $P$. vivax sporozoites and conferring moderate protection 
against a challenge test [22]. The need to develop a new strategy for improving the efficacy of a P. vivax vaccine led to the exploration of the mumps virus NP as an antigen carrier [43]. This carrier was selected after taking into account two facts: the internal protein is weakly recognized even in mumps-vaccinated individuals [31], and the P. pastoris secreted expression system was already successfully used for the expression of mumps NLPs [30]. This is described as one of the most powerful systems for recombinant protein expression, yielding proteins with high purity [44] and the ability to express viral particles in the form of VLPs [45,46]. Using the same strategy, we successfully expressed, characterized, and purified two mumps NLPs carrying PvCSP sequences that remained stable and presented the appropriate structural conformation, as evidenced by the mean diameter of the particle corresponding to mumps nucleocapsid [30], confirmed after scanning electron microscopy.

The importance of inducing high levels of PvCSP-specific antibodies was highlighted in a study comparing the immunogenicity of VMP001 with CSV-S,S, which is an RTS,S-like vaccine candidate containing hepatitis B surface antigen (HBsAg) and a protein fusing the VMP001 sequences to HBsAg [47]. Although CSV-S,S induced higher levels of PvCSP repeat variants specific antibodies than did soluble VMP001, there is a major concern about the immune responses generated against the viral components. By contrast, the mumps-NP particle present in our formulations proved to be an excellent vaccine candidate as emphasized by the low seroprevalence of the antibodies against mumps-vaccinated/exposed individuals or individuals living in P. vivax endemic areas [31], thereby avoiding the possible interference of memory cells against the viral particle. The lack of a PvCSP N-terminal domain containing CD4 $\mathrm{T}$ cell epitopes in our formulations could present a further advantage compared to VMP001, as $\mathrm{CD}^{+} \mathrm{T}$ cell responses were seen to be directed to the N-terminal region in $90 \%$ of individuals vaccinated with VMP001; this response was not protective against controlled human malaria infection [20].

The two vaccine formulations tested in this study induced high antibody titers to all three PvCSP repeat regions, being dominated by the $P$. vivax-like variant among them, in murine sera 14 days after three immunization doses. Regarding the adjuvant selected to these immunizations, Poly (I:C), it activates different pattern-recognition receptors, such as TLR3, RIG-I/MDA5, and PKR, triggering multiple inflammatory pathways, including NF-kB and IRF $[48,49]$. By eliciting an inflammatory Th1-like response in mice and humans, it was hypothesized that such a response could contribute to protection [50]. Previously, our research group showed that Poly (I:C) was responsible to enhance not only the immunogenicity of PvCSP recombinant proteins upon vaccination $[21,33]$ but also protection after a parasitic challenge [22,41]. In this study, the NLP-CSP ${ }_{R}$ vaccine formulation induced a predominance of IgG2c over IgG1. In an animal model of $P$. falciparum infection, a vaccine candidate also induced anti-CSP IgG2 antibodies which were associated with protection [51]. On the other hand, the NLP-CSP ${ }_{\text {CT }}$ protein displayed the opposite pattern, with predominance of IgG1. Thus, our data suggest that the presence of the C-terminal region of the PvCSP in NLP-CSP antigen conformation, spotlighting other epitopes related to an IgG2 response. Even so, it provided protection with decreased parasitemia and enhanced survival of immunized and challenged mice. However, it remains elusive whether a vaccine formulation with such particular responses in mice could present a similar pattern in humans and still be protective.

The high level of antibody titers in the serum is a result of the increased number of specific ASCs in the spleens of these mice 5 days after the second boost. Most of the ASCs generated after the first and second doses of the vaccine should have reached the bone marrow by day 0 following the second boost, indicating that the "basal" level of specific ASCs could already be high. In our vaccine formulation, once all three repeat variants are presented in the same chimeric protein at the same molecular ratio, differences in the kinetics of ASCs specific to P. vivax-like and no-repeats are not expected. Although the mechanism involved is not within the scope of this paper, some of the following hypotheses can be taken into consideration: (i) Some protein regions may be more available to antibody binding than others in the tertiary protein structure, which would confer an advantage for B-cell activation. This is one of the most important features of B-cell responses and has been extensively studied for antigens 
such as HA from the influenza virus and gp120 from HIV [52,53]. While the preference of the antibody response to recognize the repeat portions of the CSP during infections has also been documented, our chimeric construct combines all repeat variants into one protein and seems to prioritize the B-cell immune response to individual components that remain ambiguous [47,54]; (ii) Furthermore, the recognition of some epitopes can interfere with the availability of the antibody binding to the other epitopes. Although this a rare phenomenon, it has been documented in the antibody immunity to PfCSP in infected patients [55].

Disregarding the mechanism involved, it is undeniable that the third immunization elicited de novo ASC formation to PvCSP non-repeat regions and the P. vivax-like variant. Not all of the ASCs formed at this time point will contribute to the overall long-term immunity observed in the bone marrow, but some will and can be detected when the overall immunity is analyzed (ASC specific to PvCSP-All $_{\mathrm{CT}}$ and NLP-CSP ${ }_{\mathrm{CT}}$ ). This increase in overall long-term immunity indicates the need for a third immunization dose and may reflect on the vaccine efficacy. It is interesting to note that the same ASC response is observed against PvCSP-All $\mathrm{CT}_{\mathrm{T}}$ and NLP-CSP $\mathrm{CT}_{\mathrm{C}}$, thereby indicating that the fusion of NP with respect to the chimeric CSP protein construct did not affect the recognition of the PvCSP epitopes. Furthermore, when the different protein components were analyzed individually, no increase in the number of ASCs in the bone marrow 30 days after the third dose was observed. This suggests that efficient long-term immunity was already formed by the first and second immunization doses (serological imprinting). Hence, the third immunization dose seems to enhance the already-existing long-term immunity, being of particular importance to strengthening the immunity required to achieve memory cells that contribute to the overall protection, as is seen for the influenza vaccine [56].

Our formulation was able to confer sterile protection in approximately $30 \%$ of the animals, in addition to a significant decrease (approximately 10-fold) in the parasitemia of non-sterile protected animals. In a brief comparison with our previous results [22], although the methodology used to assess the protection was the same, there were significant differences in some points. To use an immunization route more suitable for comparison with future results in human vaccination, the i.p. route used in Gimenez et al. was changed to the s.c. route in our study. Challenge conditions were also strengthened from 4000 to 5000 sporozoites, while the parasitemia evaluation was highly improved from smear to flow cytometry, which is a more sensitive and precise methodology. For these reasons, we consider that the partial sterile protection observed in this study is at least equivalent to the previous results. Regarding other formulations that were able to confer a higher level of protection in murine models, such as Rv21 [17], the comparison is even harder: not only is the immunization route different (i.m. vs. s.c.), but transgenic parasites were also constructed using different approaches $[17,36]$ and the challenge systems vary from i.v. to s.c., respectively.

In cases of malaria caused by P. vivax, a complicating factor in the pathology of the disease is the presence of the latent form of the parasite, the hypnozoite, which is responsible for the relapses of the disease. In this regard, the 10-fold decrease in parasitemia goes beyond what is seen, as some of the sporozoites that were not able to reach the liver gave rise to hypnozoite forms. On the other hand, we were not able to test this possibility of hypnozoite production after the parasitic challenge as the transgenic $\mathrm{Pb} / \mathrm{Pv}$ parasite is still biologically $\mathrm{P}$. berghei and does not form hypnozoites in mice. Thus, the partial protection provided by this vaccine candidate may be related to multiple possibilities: (i) different folding of the vaccine antigen in comparison to the native parasitic protein, hiding or changing important epitopes related to protection; (ii) reduced $\mathrm{T}$ cell responses, critical for antibody responses; (iii) higher pathogenicity of the transgenic parasite used in the mouse challenge due to the increased amount of sporozoites inoculated and/or route of inoculation; etc. Extrapolating these data to humans, the partial protection could hypothetically contribute to a decrease in the number of relapses [57].

The number of sporozoites (spz) used in the infection model and the use of transgenic parasites $(\mathrm{Pb} / \mathrm{Pv})$ are the two other points to be considered. For the challenge test, $5000 \mathrm{spz}$ were used, which is a very high number, as in a natural infection by a mosquito bite, an individual is inoculated with less 
than $40 \mathrm{spz}$ [58]. Although malarial transgenic parasites are an important tool for elucidating vaccine efficacy, their use may produce results that underestimate vaccine efficacy. This transgenic parasite is constructed by replacing only the repeated region of the P. berghei CS protein with the corresponding amino acids of the VK210 variant of P. vivax [36]. However, the vaccine formulation in this study elicited antibodies against repeats of VK210, VK247, and P. vivax-like variants, RI and C-terminal region. The challenge test indicated only the protective efficacy of antibodies directed to the repeats of the VK210 variant. Therefore, the efficacy of the vaccine formulation developed in this study may be even greater when considered in case of a natural infection.

\section{Conclusions}

In summary, we have constructed, expressed, and purified a chimeric vaccine with a high purity level, comprising the mumps virus nucleoprotein sequence in fusion with different PvCSP allelic variants along with its C-terminal region. This vaccine formulation was able to generate high titers of specific antibodies that promoted moderate protection in infected animals. A future scope of this study would entail a detailed understanding of the mechanism by which this formulation confers partial protection. This, in turn, shall improve its efficacy for potential application as a new P. vivax vaccine.

Author Contributions: Conceptualization, I.S.S.; formal analysis, R.F.M. and A.M.G.; funding acquisition, R.A. and I.S.S.; investigation, R.F.M., A.M.G., E.A., J.T.N., D.P.C., and M.R.D.; methodology, R.F.M. and A.M.G.; project administration, I.S.S.; resources, I.-S.W. and E.L.V.S.; supervision, R.A. and I.S.S.; writing-original draft, R.F.M., A.M.G., and M.R.D.; writing-review and editing, E.L.V.S., R.A., and I.S.S. All authors have read and agreed to the published version of the manuscript.

Funding: We would like to thank Felipe Dorr and Katia Sanches Françoso for helping with biochemical analyses. We also thank Fidel Zavala for providing the chimeric Plasmodium berghei sporozoites. This paper is dedicated to Professor Mauricio M. Rodrigues (in memoriam), who conceived of the original idea of this study. This work was supported by grants from Fundação de Amparo à Pesquisa do Estado de São Paulo (FAPESP 2012/13032-5 and 2014/18102-7), National Institute of Science and Technology for Vaccines/Conselho Nacional de Desenvolvimento Científico e Tecnológico (CNPq 465293/2014-0), Institut Pasteur- Paris, and the French Government's Investissement d'Avenir program, Laboratoire d'Excellence "Integrative Biology of Emerging Infectious Diseases" (grant no. ANR-10-LABX-62-IBEID). A.M.G. and J.T.N. are recipients of a fellowship from FAPESP, R.F.M. and M.R.D. were recipients of a fellowship from Coordenação de Aperfeiçoamento de Pessoal de Ensino Superior, and I.S.S. was the recipient of a fellowship from CNPq.

Conflicts of Interest: The authors declare no conflict of interest.

\section{References}

1. World Health Organization. World Malaria Report 2018; World Health Organization: Geneva, Switzerland, 2018.

2. Price, R.N.; von Seidlein, L.; Valecha, N.; Nosten, F.; Baird, J.K.; White, N.J. Global extent of chloroquine-resistant Plasmodium vivax: A systematic review and meta-analysis. Lancet Infect. Dis. 2014, 14, 982-991. [CrossRef]

3. Villamil-Gómez, W.E.; Eyes-Escalante, M.; Franco-Paredes, C. Severe and Complicated Malaria Due to Plasmodium Vivax. In Current Topics in Malaria; InTech: London, UK, 2016. [CrossRef]

4. malERA. Consultative Group on Vaccines. A research agenda for malaria eradication: Vaccines. PLoS Med. 2011, 8, e1000398. [CrossRef]

5. Tham, W.H.; Beeson, J.G.; Rayner, J.C. Plasmodium vivax vaccine research—we've only just begun. Int. J. Parasitol. 2017, 47, 111-118. [CrossRef] [PubMed]

6. Olotu, A.; Fegan, G.; Wambua, J.; Nyangweso, G.; Awuondo, K.O.; Leach, A.; Lievens, M.; Leboulleux, D.; Njuguna, P.; Peshu, N.; et al. Four-year efficacy of RTS,S/AS01E and its interaction with malaria exposure. N. Engl. J. Med. 2013, 368, 1111-1120. [CrossRef]

7. RTS, S.C.T.P. Efficacy and safety of RTS,S/AS01 malaria vaccine with or without a booster dose in infants and children in Africa: Final results of a phase 3, individually randomised, controlled trial. Lancet 2015, 386, 31-45. [CrossRef] 
8. Dobano, C.; Sanz, H.; Sorgho, H.; Dosoo, D.; Mpina, M.; Ubillos, I.; Aguilar, R.; Ford, T.; Diez-Padrisa, N.; Williams, N.A.; et al. Concentration and avidity of antibodies to different circumsporozoite epitopes correlate with RTS,S/AS01E malaria vaccine efficacy. Nat. Commun. 2019, 10, 2174. [CrossRef]

9. Arnot, D.E.; Barnwell, J.W.; Tam, J.P.; Nussenzweig, V.; Nussenzweig, R.S.; Enea, V. Circumsporozoite protein of Plasmodium vivax: Gene cloning and characterization of the immunodominant epitope. Science 1985, 230, 815-818. [CrossRef]

10. Rosenberg, R.; Wirtz, R.A.; Lanar, D.E.; Sattabongkot, J.; Hall, T.; Waters, A.P.; Prasittisuk, C. Circumsporozoite protein heterogeneity in the human malaria parasite Plasmodium vivax. Science 1989, 245, 973-976. [CrossRef]

11. Qari, S.H.; Shi, Y.P.; Goldman, I.F.; Udhayakumar, V.; Alpers, M.P.; Collins, W.E.; Lal, A.A. Identification of Plasmodium vivax-like human malaria parasite. Lancet 1993, 341, 780-783. [CrossRef]

12. De Souza-Neiras, W.C.; de Melo, L.M.; Machado, R.L. The genetic diversity of Plasmodium vivax-A review. Mem Inst. Oswaldo Cruz 2007, 102, 245-254. [CrossRef]

13. Raza, A.; Ghanchi, N.K.; Thaver, A.M.; Jafri, S.; Beg, M.A. Genetic diversity of Plasmodium vivax clinical isolates from southern Pakistan using pvcsp and pvmsp1 genetic markers. Malaria J. 2013, 12, 16. [CrossRef] [PubMed]

14. Pereira, V.A.; Sanchez-Arcila, J.C.; Vasconcelos, M.P.A.; Ferreira, A.R.; de Souza Videira, L.; Teva, A.; Perce-da-Silva, D.; Marques, M.T.Q.; de Carvalho, L.H.; Banic, D.M.; et al. Evaluating seroprevalence to circumsporozoite protein to estimate exposure to three species of Plasmodium in the Brazilian Amazon. Infect. Dis. Poverty 2018, 7, 46. [CrossRef] [PubMed]

15. Arruda, M.E.; Zimmerman, R.H.; Souza, R.M.; Oliveira-Ferreira, J. Prevalence and level of antibodies to the circumsporozoite protein of human malaria parasites in five states of the Amazon region of Brazil. Mem. Inst. Oswaldo Cruz 2007, 102, 367-371. [CrossRef] [PubMed]

16. White, M.T.; Verity, R.; Griffin, J.T.; Asante, K.P.; Owusu-Agyei, S.; Greenwood, B.; Drakeley, C.; Gesase, S.; Lusingu, J.; Ansong, D.; et al. Immunogenicity of the RTS,S/AS01 malaria vaccine and implications for duration of vaccine efficacy: Secondary analysis of data from a phase 3 randomised controlled trial. Lancet Infect. Dis. 2015, 15, 1450-1458. [CrossRef]

17. Salman, A.M.; Montoya-Diaz, E.; West, H.; Lall, A.; Atcheson, E.; Lopez-Camacho, C.; Ramesar, J.; Bauza, K.; Collins, K.A.; Brod, F.; et al. Rational development of a protective P. vivax vaccine evaluated with transgenic rodent parasite challenge models. Sci. Rep. 2017, 7, 46482. [CrossRef]

18. Atcheson, E.; Bauza, K.; Salman, A.M.; Alves, E.; Blight, J.; Viveros-Sandoval, M.E.; Janse, C.J.; Khan, S.M.; Hill, A.V.S.; Reyes-Sandoval, A. Tailoring a Plasmodium vivax Vaccine To Enhance Efficacy through a Combination of a CSP Virus-Like Particle and TRAP Viral Vectors. Infect. Immun. 2018, 86. [CrossRef]

19. Mueller, I.; Shakri, A.R.; Chitnis, C.E. Development of vaccines for Plasmodium vivax malaria. Vaccine 2015, 33, 7489-7495. [CrossRef]

20. Bennett, J.W.; Yadava, A.; Tosh, D.; Sattabongkot, J.; Komisar, J.; Ware, L.A.; McCarthy, W.F.; Cowden, J.J.; Regules, J.; Spring, M.D.; et al. Phase 1/2a Trial of Plasmodium vivax Malaria Vaccine Candidate VMP001/AS01B in Malaria-Naive Adults: Safety, Immunogenicity, and Efficacy. PLoS Negl. Trop. Dis. 2016, 10, e0004423. [CrossRef]

21. Teixeira, L.H.; Tararam, C.A.; Lasaro, M.O.; Camacho, A.G.; Ersching, J.; Leal, M.T.; Herrera, S.; Bruna-Romero, O.; Soares, I.S.; Nussenzweig, R.S.; et al. Immunogenicity of a prime-boost vaccine containing the circumsporozoite proteins of Plasmodium vivax in rodents. Infect. Immun. 2014, 82, $793-807$. [CrossRef]

22. Gimenez, A.M.; Lima, L.C.; Francoso, K.S.; Denapoli, P.M.A.; Panatieri, R.; Bargieri, D.Y.; Thiberge, J.M.; Andolina, C.; Nosten, F.; Renia, L.; et al. Vaccine Containing the Three Allelic Variants of the Plasmodium vivax Circumsporozoite Antigen Induces Protection in Mice after Challenge with a Transgenic Rodent Malaria Parasite. Front. Immunol. 2017, 8, 1275. [CrossRef]

23. Frietze, K.M.; Peabody, D.S.; Chackerian, B. Engineering virus-like particles as vaccine platforms. Curr. Opin. Virol. 2016, 18, 44-49. [CrossRef]

24. Fuenmayor, J.; Godia, F.; Cervera, L. Production of virus-like particles for vaccines. N Biotechnol. 2017, 39, 174-180. [CrossRef] [PubMed]

25. Cimica, V.; Galarza, J.M. Adjuvant formulations for virus-like particle (VLP) based vaccines. Clin. Immunol. 2017, 183, 99-108. [CrossRef] [PubMed] 
26. Liu, J.; Dai, S.; Wang, M.; Hu, Z.; Wang, H.; Deng, F. Virus like particle-based vaccines against emerging infectious disease viruses. Virol. Sin. 2016, 31, 279-287. [CrossRef] [PubMed]

27. Crisci, E.; Barcena, J.; Montoya, M. Virus-like particles: The new frontier of vaccines for animal viral infections. Vet. Immunol. Immunopathol. 2012, 148, 211-225. [CrossRef] [PubMed]

28. Dai, S.; Wang, H.; Deng, F. Advances and Challenges in Enveloped Virus-like Particle (VLP)-Based Vaccines. J. Immunol. Sci. 2018, 2, 36-41.

29. Sekaly, R.P. The failed HIV Merck vaccine study: A step back or a launching point for future vaccine development? J. Exp. Med. 2008, 205, 7-12. [CrossRef]

30. Slibinskas, R.; Zvirbliene, A.; Gedvilaite, A.; Samuel, D.; Jin, L.; Beard, S.; Staniulis, J.; Sasnauskas, K. Synthesis of mumps virus nucleocapsid protein in yeast Pichia pastoris. J. Biotechnol. 2003, 103, 43-49. [CrossRef]

31. Allwinn, R.; Zeidler, B.; Steinhagen, K.; Rohwader, E.; Wicker, S.; Rabenau, H.F.; Doerr, H.W. Assessment of mumps virus-specific antibodies by different serological assays: Which test correlates best with mumps immunity? Eur J. Clin. Microbiol Infect. Dis. 2011, 30, 1223-1228. [CrossRef]

32. Jacob, D.; Ruffie, C.; Dubois, M.; Combredet, C.; Amino, R.; Formaglio, P.; Gorgette, O.; Pehau-Arnaudet, G.; Guery, C.; Puijalon, O.; et al. Whole Pichia pastoris yeast expressing measles virus nucleoprotein as a production and delivery system to multimerize Plasmodium antigens. PLoS ONE 2014, 9, e86658. [CrossRef]

33. Leal, M.T.; Camacho, A.G.; Teixeira, L.H.; Bargieri, D.Y.; Soares, I.S.; Tararam, C.A.; Rodrigues, M.M. Immunogenicity of recombinant proteins consisting of Plasmodium vivax circumsporozoite protein allelic variant-derived epitopes fused with Salmonella enterica Serovar Typhimurium flagellin. Clin. Vaccine Immunol. 2013, 20, 1418-1425. [CrossRef] [PubMed]

34. Rocha, M.V.; Francoso, K.S.; Lima, L.C.; Camargo, T.M.; Machado, R.L.D.; Costa, F.T.M.; Renia, L.; Nosten, F.; Russell, B.; Rodrigues, M.M.; et al. Generation, characterization and immunogenicity of a novel chimeric recombinant protein based on Plasmodium vivax AMA-1 and MSP119. Vaccine 2017, 35, 2463-2472. [CrossRef] [PubMed]

35. Fabris, A.L.; Nunes, A.V.; Schuch, V.; de Paula-Silva, M.; Rocha, G.; Nakaya, H.I.; Ho, P.L.; Silveira, E.L.V.; Farsky, S.H.P. Hydroquinone exposure alters the morphology of lymphoid organs in vaccinated C57Bl/6 mice. Environ. Pollut 2020, 257, 113554. [CrossRef] [PubMed]

36. Espinosa, D.A.; Yadava, A.; Angov, E.; Maurizio, P.L.; Ockenhouse, C.F.; Zavala, F. Development of a chimeric Plasmodium berghei strain expressing the repeat region of the P. vivax circumsporozoite protein for in vivo evaluation of vaccine efficacy. Infect. Immun. 2013, 81, 2882-2887. [CrossRef] [PubMed]

37. Aliprandini, E.; Tavares, J.; Panatieri, R.H.; Thiberge, S.; Yamamoto, M.M.; Silvie, O.; Ishino, T.; Yuda, M.; Dartevelle, S.; Traincard, F.; et al. Cytotoxic anti-circumsporozoite antibodies target malaria sporozoites in the host skin. Nat. Microbiol. 2018, 3, 1224-1233. [CrossRef]

38. Apostolico Jde, S.; Lunardelli, V.A.; Coirada, F.C.; Boscardin, S.B.; Rosa, D.S. Adjuvants: Classification, Modus Operandi, and Licensing. J. Immunol. Res. 2016, 2016, 1459394. [CrossRef]

39. Silveira, E.L.; Kasturi, S.P.; Kovalenkov, Y.; Rasheed, A.U.; Yeiser, P.; Jinnah, Z.S.; Legere, T.H.; Pulendran, B.; Villinger, F.; Wrammert, J. Vaccine-induced plasmablast responses in rhesus macaques: Phenotypic characterization and a source for generating antigen-specific monoclonal antibodies. J. Immunol. Methods 2015, 416, 69-83. [CrossRef]

40. Kasturi, S.P.; Kozlowski, P.A.; Nakaya, H.I.; Burger, M.C.; Russo, P.; Pham, M.; Kovalenkov, Y.; Silveira, E.L.V.; Havenar-Daughton, C.; Burton, S.L.; et al. Adjuvanting a Simian Immunodeficiency Virus Vaccine with Toll-Like Receptor Ligands Encapsulated in Nanoparticles Induces Persistent Antibody Responses and Enhanced Protection in TRIM5alpha Restrictive Macaques. J. Virol. 2017, 91. [CrossRef]

41. de Camargo, T.M.; de Freitas, E.O.; Gimenez, A.M.; Lima, L.C.; de Almeida Caramico, K.; Francoso, K.S.; Bruna-Romero, O.; Andolina, C.; Nosten, F.; Renia, L.; et al. Prime-boost vaccination with recombinant protein and adenovirus-vector expressing Plasmodium vivax circumsporozoite protein (CSP) partially protects mice against $\mathrm{Pb} / \mathrm{Pv}$ sporozoite challenge. Sci. Rep. 2018, 8, 1118. [CrossRef]

42. Mohsen, M.O.; Zha, L.; Cabral-Miranda, G.; Bachmann, M.F. Major findings and recent advances in virus-like particle (VLP)-based vaccines. Semin. Immunol. 2017, 34, 123-132. [CrossRef]

43. Kingston, R.L.; Baase, W.A.; Gay, L.S. Characterization of nucleocapsid binding by the measles virus and mumps virus phosphoproteins. J. Virol. 2004, 78, 8630-8640. [CrossRef] [PubMed] 
44. Wang, M.; Jiang, S.; Wang, Y. Recent advances in the production of recombinant subunit vaccines in Pichia pastoris. Bioengineered 2016, 7, 155-165. [CrossRef] [PubMed]

45. Shukla, R.; Rajpoot, R.K.; Arora, U.; Poddar, A.; Swaminathan, S.; Khanna, N. Pichia pastoris-Expressed Bivalent Virus-Like Particulate Vaccine Induces Domain III-Focused Bivalent Neutralizing Antibodies without Antibody-Dependent Enhancement in Vivo. Front. Microbiol. 2017, 8, 2644. [CrossRef] [PubMed]

46. Saraswat, S.; Athmaram, T.N.; Parida, M.; Agarwal, A.; Saha, A.; Dash, P.K. Expression and Characterization of Yeast Derived Chikungunya Virus Like Particles (CHIK-VLPs) and Its Evaluation as a Potential Vaccine Candidate. PLoS Negl. Trop. Dis. 2016, 10, e0004782. [CrossRef]

47. Vanloubbeeck, Y.; Pichyangkul, S.; Bayat, B.; Yongvanitchit, K.; Bennett, J.W.; Sattabongkot, J.; Schaecher, K.; Ockenhouse, C.F.; Cohen, J.; Yadava, A.; et al. Comparison of the immune responses induced by soluble and particulate Plasmodium vivax circumsporozoite vaccine candidates formulated in AS01 in rhesus macaques. Vaccine 2013, 31, 6216-6224. [CrossRef]

48. Yu, M.; Levine, S.J. Toll-like receptor, RIG-I-like receptors and the NLRP3 inflammasome: Key modulators of innate immune responses to double-stranded RNA viruses. Cytokine Growth Factor Rev. 2011, 22, 63-72. [CrossRef]

49. Yamamoto, M.; Sato, S.; Hemmi, H.; Hoshino, K.; Kaisho, T.; Sanjo, H.; Takeuchi, O.; Sugiyama, M.; Okabe, M.; Takeda, K.; et al. Role of adaptor TRIF in the MyD88-independent toll-like receptor signaling pathway. Science 2003, 301, 640-643. [CrossRef]

50. Perez-Mazliah, D.; Langhorne, J. CD4 T-cell subsets in malaria: TH1/TH2 revisited. Front. Immunol. 2014, 5, 671. [CrossRef]

51. Schwenk, R.; DeBot, M.; Porter, M.; Nikki, J.; Rein, L.; Spaccapelo, R.; Crisanti, A.; Wightman, P.D.; Ockenhouse, C.F.; Dutta, S. IgG2 antibodies against a clinical grade Plasmodium falciparum CSP vaccine antigen associate with protection against transgenic sporozoite challenge in mice. PLoS ONE 2014, 9, e111020. [CrossRef]

52. Angeletti, D.; Gibbs, J.S.; Angel, M.; Kosik, I.; Hickman, H.D.; Frank, G.M.; Das, S.R.; Wheatley, A.K.; Prabhakaran, M.; Leggat, D.J.; et al. Defining B cell immunodominance to viruses. Nat. Immunol. 2017, 18, 456-463. [CrossRef]

53. Angeletti, D.; Kosik, I.; Santos, J.J.S.; Yewdell, W.T.; Boudreau, C.M.; Mallajosyula, V.V.A.; Mankowski, M.C.; Chambers, M.; Prabhakaran, M.; Hickman, H.D.; et al. Outflanking immunodominance to target subdominant broadly neutralizing epitopes. Proc. Natl. Acad. Sci. USA 2019, 116, 13474-13479. [CrossRef] [PubMed]

54. Yadava, A.; Waters, N.C. Rationale for Further Development of a Vaccine Based on the Circumsporozoite Protein of Plasmodium vivax. PLoS Negl. Trop. Dis. 2017, 11, e0005164. [CrossRef] [PubMed]

55. Kisalu, N.K.; Idris, A.H.; Weidle, C.; Flores-Garcia, Y.; Flynn, B.J.; Sack, B.K.; Murphy, S.; Schon, A.; Freire, E.; Francica, J.R.; et al. A human monoclonal antibody prevents malaria infection by targeting a new site of vulnerability on the parasite. Nat. Med. 2018, 24, 408-416. [CrossRef] [PubMed]

56. Lee, J.; Paparoditis, P.; Horton, A.P.; Fruhwirth, A.; McDaniel, J.R.; Jung, J.; Boutz, D.R.; Hussein, D.A.; Tanno, Y.; Pappas, L.; et al. Persistent Antibody Clonotypes Dominate the Serum Response to Influenza over Multiple Years and Repeated Vaccinations. Cell Host Microbe 2019, 25, 367-376 e365. [CrossRef] [PubMed]

57. White, M.; Amino, R.; Mueller, I. Theoretical Implications of a Pre-Erythrocytic Plasmodium vivax Vaccine for Preventing Relapses. Trends Parasitol. 2017, 33, 260-263. [CrossRef]

58. Rosenberg, R.; Wirtz, R.A.; Schneider, I.; Burge, R. An estimation of the number of malaria sporozoites ejected by a feeding mosquito. Trans. $R$ Soc. Trop. Med. Hyg. 1990, 84, 209-212. [CrossRef]

(C) 2020 by the authors. Licensee MDPI, Basel, Switzerland. This article is an open access article distributed under the terms and conditions of the Creative Commons Attribution (CC BY) license (http://creativecommons.org/licenses/by/4.0/). 